\title{
STRATEGI PROMOSI KESEHATAN TERHADAP UPAYA PENANGGULANGAN PENYALAHGUNAAN NARKOBA
}

\section{HEALTH PROMOTION STRATEGY AGAINST DRUG ABUSE PREVENTION EFFORTS}

\author{
Rama Nur Kurniawan. K \\ Fakultas Kesehatan Masyarakat Universitas Pancasakti Makassar, Indonesia \\ Email Korespondensi : rama.nur@mail.ugm.ac.id
}

\begin{abstract}
Abstrak
Narkoba merupakan salah satu masalah kesehatan masyarakat Indonesia yang penyalahgunaannya cenderung meningkat. Sementara ada sekitar 200 juta orang meninggal dunia setiap tahunnya disebabkan peyalahgunaan narkoba. Penelitian ini bertujuan untuk memperoleh informasi tentang bagaimana strategi promosi kesehatan terhadap upaya penanggulangan penyalahgunaan narkoba di Dinas Kesehatan Kabupaten Wajo. Penelitian ini menggunakan metode kualitatif yang sifatnya mengeksplorasi informasi dari informan sehubungan dengan strategi promosi kesehatan terhadap upaya penanggulangan penyalahgunaan narkoba di Dinas Kesehatan Kabupaten Wajo. Dari hasil penelitian menunjukkan : (1). Advokasi yang dilakukan Dinas Kesehatan Kabupaten Wajo dengan cara mengusulkan bantuan dana kepada Pemeerintah Daerah, untuk keperluan kegiatan penyuluhan napza di sekolah. (2). Kemitraan yang dilakukan Dinas Kesehatan terhadap upaya penanggulangan narkoba dengan membangun kerjasama dengan pihak polres, sekolah, puskesmas dan pemda. (3). Pemberdayaan yang dilakukan dinas kesehatan dan puskesmas, dengan membentuk kader kesehatan remaja di sekolah sebagai bentuk keikutsertaan siswa dalam memberantas narkoba di Kabupaten Wajo.
\end{abstract}

Kata Kunci : Strategi promosi kesehatan, penyalahgunaan narkoba

\begin{abstract}
Drugs is one of the Indonesian public health problems that abuse tends to increase. While there are about 200 million people die each year due to drug abuse. This study aims to obtain information about how the strategy of health promotion of drug abuse prevention efforts in the District Health Office Wajo. This study uses qualitative methods that are exploring information from informants in connection with health promotion strategies against drug abuse prevention efforts in Wajo District Health Office. From the results of the study showed: (1). Advocacy by Wajo District Health Office by proposing funding to the local government for the purpose of drug counseling activities in schools. (2). Partnerships made by the Department of Health against drug control efforts by building cooperation with the police, schools, health centers and local government. (3). Empowerment is done by health service and health center, by forming cadre of adolescent health in school as a form of student participation in eradicating drugs in Wajo Regency.
\end{abstract}

Keywords: Health promotion strategy, drug abuse 


\section{PENDAHULUAN}

Narkoba merupakan salah satu masalah kesehatan masyarakat Indonesia yang penyalahgunaannya cenderung meningkat. Laporan perkembangan situasi narkoba dunia United Nations Office on Drugs and Crime tahun 2014 diketahui angka estimasi pengguna narkoba di tahun 2012 adalah 162 juta hingga 324 juta orang. ${ }^{1}$ Jenis yang paling banyak digunakan adalah ganja, opiod, cocain atau type amphetamine dan kelompok stimulant. Menurut laporan (BNN, 2014) di Indonesia diperkirakan jumlah penyalahguna narkoba setahun terakhir sekitar 3,1 juta sampai 3,6 juta orang atau setara dengan 1,9\% dari populasi penduduk berusia 10-59 tahun di tahun 2008. ${ }^{2}$

Berdasarkan BNNP di tahun 2012, Sulawesi Selatan menempati peringkat empat besar pengguna narkoba. Kemudian di tahun 2013 menempati peringkat pertama, dengan jumlah kasus untuk pengguna narkoba yakni Kabupaten Sidrap 80 tersangka, Kabupaten Pinrang dengan 53 tersangka, serta Kabupaten Wajo 30 tersangka. Kabupaten Wajo kini menempati urutan 3 penyalahgunaan narkoba di Provinsi Sulawesi Selatan setelah Kabupaten Sidrap dan Kabupaten Bone. ${ }^{3}$

Dalam menanggulangi penyalahgunaan narkoba, maka diperlukan langkah strategik yang kemudian dikenal sebagai strategi promosi kesehatan. ${ }^{4}$ Strategi ini meliputi kegiatan advokasi, dukungan social (social support) dan pemberdayaan masyarakat (empowerment) serta didukung oleh kemitraan. ${ }^{5}$ Pelaksanaan strategi ini bertujuan untuk lebih memaksimalkan penerapan upaya promosi kesehatan dan pemberdayaan masyarakat, agar masyarakat mampu secara bersama-sama dalam menanggulangi kesehatan, khusunya penyalahgunaan narkoba. ${ }^{6}$

Dari uraian diatas bahwa penelitian ini bertujuan untuk memperoleh informasi tentang bagaimana strategi promosi kesehatan terhadap upaya penanggulangan penyalahgunaan narkoba di Dinas Kesehatan Kabupaten Wajo.

\section{METODE}

Penelitian ini merupakan jenis penelitian kualitatif yang sifatnya mengeksplorasi informasi dari informan sehubungan dengan strategi promosi kesehatan terhadap upaya penanggulangan penyalahgunaan narkoba di Dinas Kesehatan Kabupaten Wajo. Metode pengumpulan data dilakukan dengan menggunakan metode observasi partisipasi, wawancara mendalam dan Diskusi Kelompok Terarah (DKT). Pengumpulan data dilakukan dengan metode wawancara mendalam (indept Interview). Informan yang berhasil diwawancarai sebanyak 5 orang dengan karakteristik yaitu, 2 orang dari pihak Polres Kabupaten Wajo, 1 orang dari Dinas Kesehatan, 1 orang dari pihak Puskesmas dan 1 orang siswa.

\section{HASIL DAN PEMBAHASAN}

Hasil penelitian yang dilakukan menemukan strategi promosi kesehatan yang diterapkan oleh Dinas Kesehatan Kabupaten Wajo terkait upaya penanggulangan narkoba, antara lain sebagai berikut :

\section{Advokasi}

Strategi advokasi yang dilakukan oleh Dinas Kesehatan Kabupaten Wajo, berupa bentuk pengusulan bantuan dana ke Pemerintah Daerah. Tujuan dari pengusulan bantuan dana ini akan digunakan untuk melakukan penyuluhan kesehatan yang berkaitan dengan narkotika, psikotropika dan zat adiktif lainnya (napza).

Keberhasilan sebuah advokasi dapat dilihat dari tenaga advokator yang mampu memperoleh dukungan, yang dipengaruhi oleh kemampuannya dalam melakukan komunikasi interpersonal untuk mengajukan usulan maupun tawaran konsep kepada pemberi kebijakan dalam hal ini Pemerintah Daerah(7). Menurut Notoatmodjo (2005 dalam Ricky Saida, 2012) bahwa dalam advokasi, peran komunikasi sangat penting sebab advokasi merupakan aplikasi dari komunikasi interpersonal maupun massa yang ditujukan kepada para penentu kebijakan (policy makers) atau pada pembuat keputusan (decission makers) pada semua tingkat dan tatanan sosial.

Menurut "John Hopkins, (1990) menjelaskan advokasi sebagai usaha untuk mempengaruhi kebijakan melalui bermacam-macam bentuk komunikasi persuasif, dengan menggunakan informasi yang akurat dan tepat. $^{8}$

\section{Kemitraan}

Selain melakukan tahap advokasi, Dinkes selanjutnya membangun strategi kemitraan. Strategi ini dijalankan dengan bekerjasama dengan beberapa instansi terkait, yang dianggap mampu membantu proses penanggulangan narkoba di Kabupaten Wajo. Adapun instansi yang terlibat kerjasma lintas sektor yaitu puskesmas, sekolah dan polres.

Bentuk kemitraan yang dilakukan antara dinas kesehatan dan puskesmas berupa penyuluhan kepada anak sekolah yang bertujuan menambah tingkat pengetahuan siswa tentang dampak napza bagi kesehatan, sehingga diharapkan terciptanya pemberdayaan siswa terhadap penanggulangan narkoba berupa pembentukan kader kesehatan remaja.

Bentuk kemitraan yang dilakukan antara dinas kesehatan dan sekolah dalam penanggulangan narkoba yaitu membatu mengumpulkan siswa pada saat dinas kesehatan melakukan penyuluhan di sekolah.

Bentuk kemitraan yang dilakukan antara dinas kesehatan dan polres berupa penyuluhan bersama yang dilakukan disekolah dengan tujuan menigkatkan pengetahuan siswa tentang bahaya napza dan undang-undang tindak penyalahgunaan narkoba serta lama kurungan.

Kemitraan merupakan jalinan kerjasama usaha yang merupakan strategi bisnis yang dilakukan antara dua pihak atau lebih dengan prinsip saling membutuhkan, saling memperbesar dan saling menguntungkan. ${ }^{9}$

Berdasarkan hasil penelitian yang dilakukan, diperoleh informasi mengenai manfaat kemitraan yang disampaikan oleh informan berupa terciptanya efektifitas penyuluhan, pekerjaan terasa ringan dan dianggap mampu membantu pemberantasan narkoba.

Strategi penanggulangan narkoba selain dil- 
akukan oleh dinas kesehatan, juga dilakukan oleh polres selaku pihak penegak hukum, dengan cara melakukan sosialisasi serta menerapkan kebijakan yang mengacu pada kitab undang-undang hukum pidana (KUHP) tentang tindak penyalahgunaan narkoba.

Hal ini senada dengan apa yang dikemukakan oleh (Hasrat Jaya Siliwu, (2007), bahwa kemitraan adalah suatu kerjasama formal antara individu-individu, kelompok-kelompok atau organisasi-organisasi untuk mencapai suatu tugas atau tujuan tertentu. ${ }^{10}$ Konsep kemitraan merupakan upaya melibatkan berbagai komponen baik sektor, kelompok, masyarakat, lembaga pemerintah atau non pemerintah untuk bekerjasama mencapai tujuan bersama berdasarkan atas kesepakatan, prinsip dan peran masing-masing. ${ }^{11}$

\section{Pemberdayaan}

Pemberdayaaan yang dilakukan dinas kesehatan terhadap upaya penanggulangan narkoba dengan cara membentuk kader kesehatan remaja di sekolah. Tujuannya adalah memberikan pemahaman terhadap siswa tentang bahaya penyalahgunaan napza bagi kesehatan, sehingga sehingga siswa memiliki kesadaran untuk ikut terlibat memerangi tindak penyalahgunaan narkoba.

Hal ini senada dengan peneliti sebelumnya yang menjelaskan bahwa pemberdayaan masyarakat bidang kesehatan adalah upaya atau proses untuk menumbuhkan kesadaran kemauan dan kemampuan dalam memelihara dan meningkatkan kesehatan. ${ }^{12}$

Pembentukan kader kesehatan remaja yang ditujukan kepada siswa diharapkan dapat menumbuhkan partisipasi aktif dari siswa akan pentingnya penanggulangan narkoba dalam segala aktivitasnya sehari-hari. Partisipasi yang bertanggung jawab sebaiknya dimiliki setiap masyarakat dan organisasi lokal. ${ }^{13}$ Partisipasi dapat dicapai bila mengetahui dengan jelas apa yang diharapkan dari kegiatan yang dilakukan. Dengan sendiriya dibutuhkan pembagian tugas pada masingmasing anggota dalam organisasi tersebut. ${ }^{\text {14-15 }}$

\section{KESIMPULAN}

Pada penelitian ini menyimpulkan bahwa Advokasi yang dilakukan Dinas Kesehatan Kabupaten Wajo dengan cara mengusulkan bantuan dana kepada Pemeerintah Daerah, untuk keperluan kegiatan penyuluhan napza di sekolah. Kemudian kemitraan yang dilakukan Dinas Kesehatan terhadap upaya penanggulangan narkoba dengan membangun kerjasama dengan pihak polres, sekolah, puskesmas dan pemda. Serta Pemberdayaan yang dilakukan dinas kesehatan dan puskesmas, dengan membentuk kader kesehatan remaja di sekolah sebagai bentuk keikutsertaan siswa dalam memberantas narkoba di Kabupaten Wajo. Olehnya itu diharapkan kepada penanggung jawab penanggulangan narkoba Dinas Kesehatan Kabupaten Wajo agar lebih melibatkan masyarakat dalam memerangi narkoba yang tidak hanya berfokus ke anak sekolah dan perlunya memaksimalkan dukungan social (social support) dengan lebih memperbanyak kerjasama terhadap organisasi kepemudaan.

\section{DAFTAR PUSTAKA}

1. Sabarinah. U \& dkk. (2015). Laporan Akhir Survey Nasional Perkembangan Penyalagunaan Narkoba Tahun Anggaran 2014. BNN-Republik Indonesia, Volume 4 (29), 100.

2. Friscilia, Y. (2015). Penyalahgunaan Narkoba Pada Kalangan Remaja di Desa Batukarang, Kecamatan Payung, Kabupaten Karo. Universitas Sumatra Utara.

3. Saida, R. N. (2013). Strategi Promosi Kesehatan Terhadap Upaya Pencegahan Penyakit Demam Berdarah Pada Wilayah Kerja Puskesmas Pertiwi Kecamatan Mariso Kota Makassar. Universitas Pancasakti.

4. Kuron, M. C. (2011). Analisis Pelaksanaan Program Promosi Kesehatan Di Puskesmas Bahu Kecamatan Malalayang Kota Manado, 2011.

5. Notoatmodjo, S. (2005). Promosi Kesehatan Teori dan Aplikasi (Cetakan Pertama). Jakarta: Rineka Cipta.

6. Saiful, F. (2011). Upaya Strategi Promosi Kesehatan Dalam Pencegahan Penyalahgunaan Narkoba Di SMA 3 Mamuju Propinsi Sulawesi Barat 2011. Universitas Hasanuddin.

7. BKKBN. 2002. Buku Sumber Untuk Advokasi. BKKBN dan UNFPA.

8. Lilfitriyani, H. (2014). Intervensi Advokasi Sebagai Upaya Implementasi Kebijakan KTR (Kawasan Tanpa Rokok) di Majelis dikdasmenmuhammadiyah.

9. Rezeki, S. (2013). Strategi Promosi Kesehatan Terhadap Peningkatan Perilaku Hidup Bersih dan Sehat Individu Pada Masyarakat Perkebunan di Wilayah Puskesmas Sei Kijang Kabupaten Pelalawan. Jurnal Ilmu Lingkungan, 38-48.

10. Kuswidanti. (2008). Gambaran Kemitraan Lintas Sektor Dan Organisasi Di Bidang Kesehatan dalam Upaya Penanganan Flu Burung di Bidang Komunikasi Komite Nasional Flu Burung Dan Pandemi Influenza (Komnas FBPI).

11. Fahrudin, A. (2010). Advokasi Pekerjaan Sosial. Sekolah Tinggi Kesejahteraan Sosial Bandung.

12. Ahmad, F. (2015). Towards Community Empowerment for Poverty Reduction in Rural Afghanistan. Ritsumeikan Journal of Asia Pacific Studies, Vol 34.

13. Azkha, N. 2013. Studi Efektivitas Penerapan Kebijakan PERDA Kota Tentang Kawasan Tanpa Rokok (KTR) dalam Upaya Menurunkan Perokok Aktif di Sumatera Barat Tahun 2013. Padang: Fakultas Kesehatan Masyarakat Universitas Andalas.

14. Ambadar, Jackie. 2008. Corporate Social Responsibility dalam Praktek di Indonesia. Jakarta: PT. Elex Media Komputindo.

15. Noor ARAC, Andri M, Yani A, Sudirman S. Legal Aspects Occupational Safety and Health of the Work Force in the Bussiness Of Dinamis Abadi City Of Palu. PROMOTIF: Jurnal Kesehatan Kesehatan Masyarakat. 2017;7(2):131-135. 


\section{Submit your next manuscript to MPPKI}

- We accept pre-submission inquiries

- Our selector tool helps you to find the most relevant journal

- We provide round the clock customer support

- Convenient online submission

- Maximum visibility for your research

Submit your manuscript at

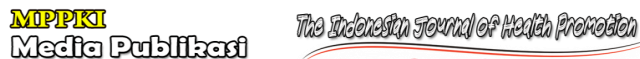

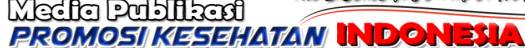

